Supporting Information

\title{
Orientation Direction Control in Liquid Crystalline Photoalignable Polymeric Films by Adjusting the Free-Surface Condition
}

Kazutoshi Miyake ${ }^{\mathrm{a}}$, Hiromi Ikoma ${ }^{\mathrm{a}}$, Makoto Okada ${ }^{\mathrm{b}}$, Shinji Matsui ${ }^{\mathrm{b}}$, Mizuho Kondo ${ }^{\mathrm{a}}$, Nobuhiro Kawatsuki ${ }^{\text {a* }}$

${ }^{a}$ Department of Applied Chemistry, Graduate School of Engineering, University of Hyogo, 2167 Shosha, Himeji, Hyogo 671-2280, Japan

${ }^{b}$ Laboratory of Advanced Science and Technology for Industry, University of Hyogo, 3-1-2 Koto, Kamigori, Ako, Hyogo 678-1205 Japan

\section{Experimental}

1.1. Film preparation and photoreaction. Thin LCP films (approximately $0.2-\mu \mathrm{m}$ thick) were prepared by spin-coating a methylene chloride solution of polymers $(2.0$ w/w\%) onto quartz or $\mathrm{CaF}_{2}$ substrates. A high-pressure $\mathrm{Hg}$ lamp equipped with a glass plate placed at Brewster's angle and a 365-nm band-pass filter (Asahi Spectra REX-250) were used for the photoreactions. The light intensity at $365 \mathrm{~nm}$ was 30 $\mathrm{mW} / \mathrm{cm}^{2}$.

1.2. Characterization. ${ }^{1} \mathrm{H}-\mathrm{NMR}$ spectra using a Bruker DRX-500 FT-NMR and FT-IR spectra (JASCO FTIR-410) confirmed the polymer. The molecular weights of the polymers were measured by GPC (Tosoh HLC-8020 GPC system with a Tosoh TSKgel column using chloroform as the eluent) calibrated using polystyrene standards. The thermal properties were examined using a polarization optical microscope (POM; Olympus BX51) equipped with a Linkam TH600PM heating and cooling stage as well as differential scanning calorimetry (DSC; Seiko-I SSC5200H). The polarized absorption UV-vis and FT-IR spectra were measured with a Hitachi U-3010 spectrometer equipped with Glan-Taylor polarization prisms and an FTIR-410 system, respectively.

As a measure of the photoinduced optical anisotropy, the photoinduced in-plane dichroic ratio (DR) was evaluated using the polarization absorption spectra, which is estimated as

$$
D R=\frac{A_{\perp}-A_{\|}}{A_{\perp}+A_{\|}},
$$


where $A_{\|}$and $A_{\perp}$ are the absorbances parallel and perpendicular to polarization (E) of LP 365-nm light, respectively.

The surface topology was evaluated using atomic force microscopy (AFM; E-sweep/NanoNavi, Hitachi High-Tech Science Co., tapping mode for $5 \times 5 \mu \mathrm{m}^{2}$ area) and an optical surface profiler (VertScan2.0 R3300, Ryoka Systems Inc., 95×95 $\mu \mathrm{m}^{2}$ or $235 \times 176 \mu \mathrm{m}^{2}$ area).

1.3. Inkjet printing. Top coating of AN molecules on PNBAM films was performed using an inkjet apparatus (LabJet-1000, MICROJET Co. Ltd) from AN/ethylene glycol solution $(20 \mathrm{wt} / \mathrm{vol}-\%)$ at $30{ }^{\circ} \mathrm{C}$. After printing $\mathrm{AN}$, the films were annealed at $100{ }^{\circ} \mathrm{C}$ for $2 \mathrm{~min}$.

\section{Supporting Figures}
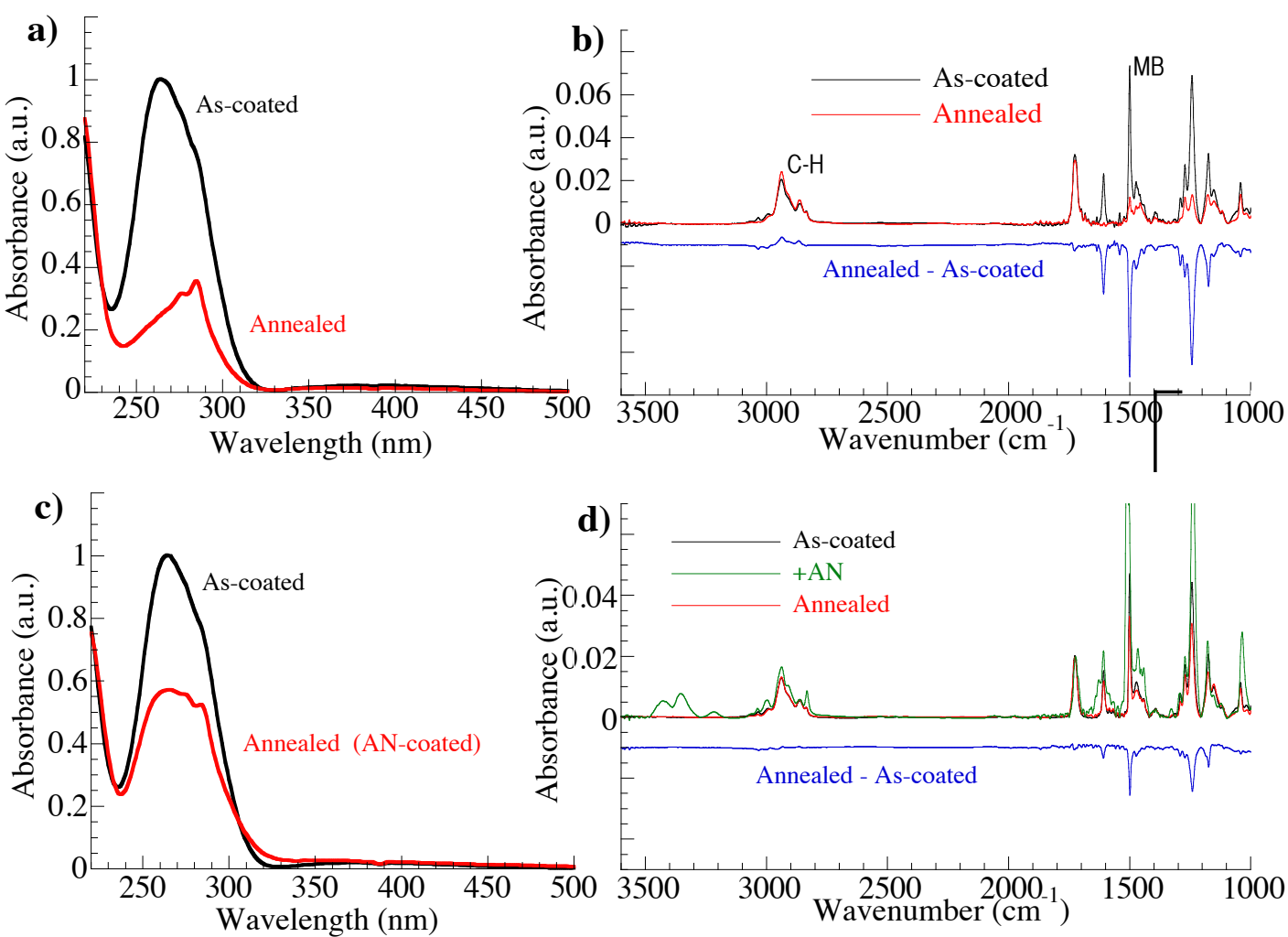

Figure S1. Changes in (a) the UV-vis absorption and (b) the FT-IR spectra of the PMBM film before and after annealing at $110^{\circ} \mathrm{C}$. Changes in (c) the UV-vis absorption and (d) the FT-IR spectra of the as-coated and AN-coated PMBM film before and after annealing at $110{ }^{\circ} \mathrm{C}$. Black (red) line is the absorption spectrum of the as-coated (annealed) film, while the blue line is the differential spectrum before and after annealing. Green lines in (d) is the absorption after coating with AN. 


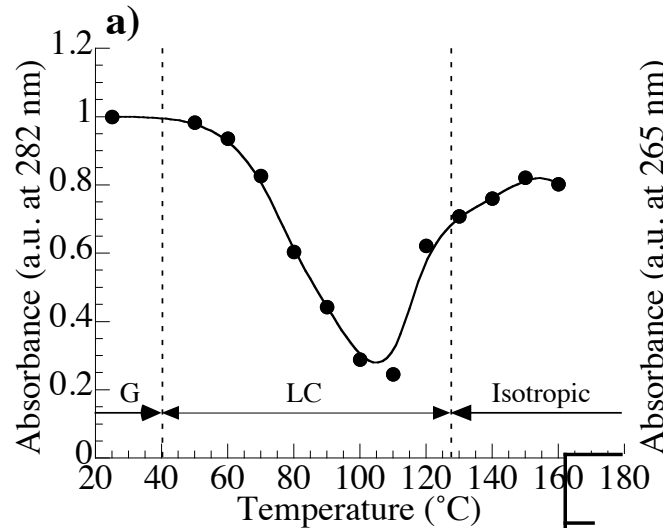

b)

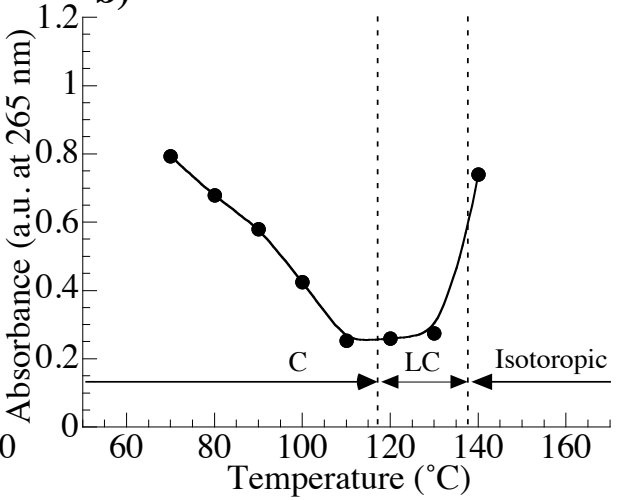

Figure S2. Changes in the absorbance (a) at $282 \mathrm{~nm}$ of PNBAM and (b) at $265 \mathrm{~nm}$ of the PMBM films annealed at various temperatures for $2 \mathrm{~min}$.
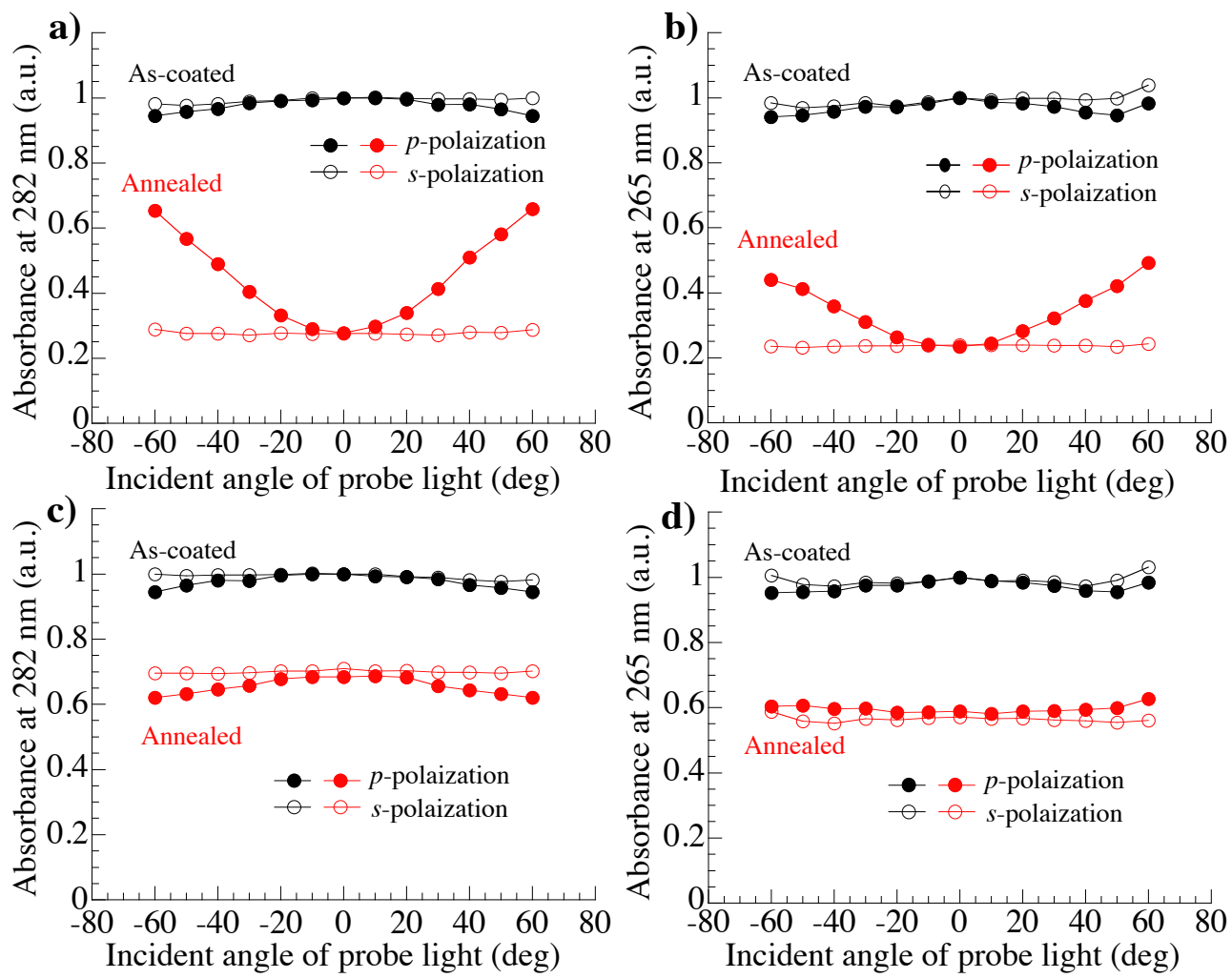

Figure S3. (a,b) Angular dependences of the absorbance at $282(265) \mathrm{nm}$ of the PNBAM (PMBM) film before and after annealing at $100(110){ }^{\circ} \mathrm{C}$ for $2 \mathrm{~min}$. (c,d) Angular dependences of the absorbance at 282 (265) $\mathrm{nm}$ of the AN-coated PNBAM (PMBM) film before and after annealing at $100(110){ }^{\circ} \mathrm{C}$ for $2 \mathrm{~min}$. 
a)

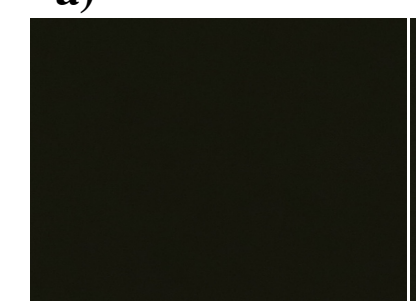

b)

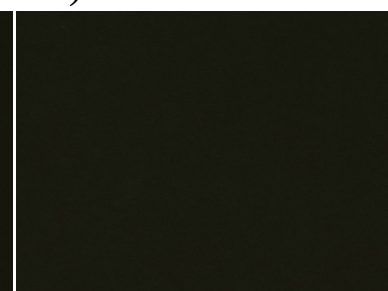

c)

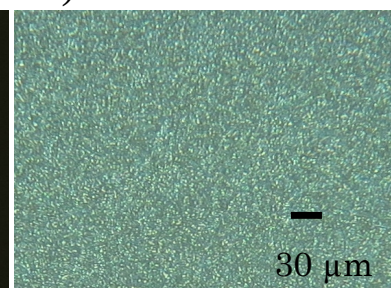

Figure S4. POM photographs of the PNBAM films under crossed polarizers. As-coated film (a) before and (b) after annealing at $100{ }^{\circ} \mathrm{C}$. (c) AN-coated film annealed at $100{ }^{\circ} \mathrm{C}$.

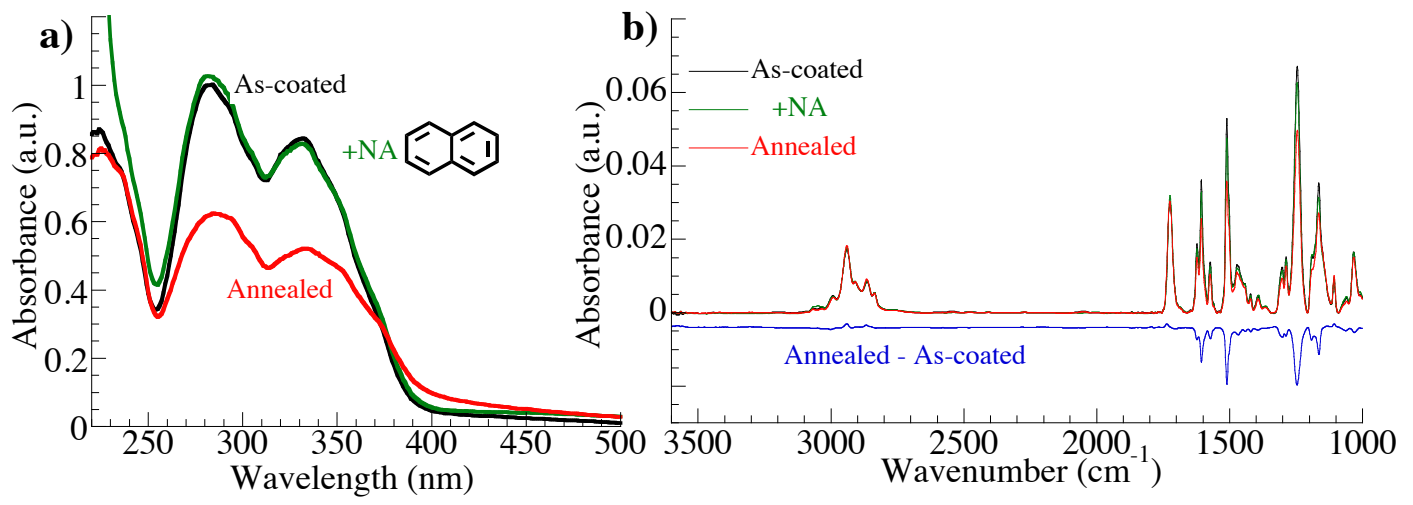

Figure S5. Changes in (a) the UV-vis absorption and (b) the FT-IR spectra of an as-coated, NA-coated PNBAM film, and after annealing at $100{ }^{\circ} \mathrm{C}$. Black (red) line is the absorption spectrum of a as-coated (annealed) film, while the blue line is the difference spectrum before and after annealing. Green line is the absorption after coating with NA. 

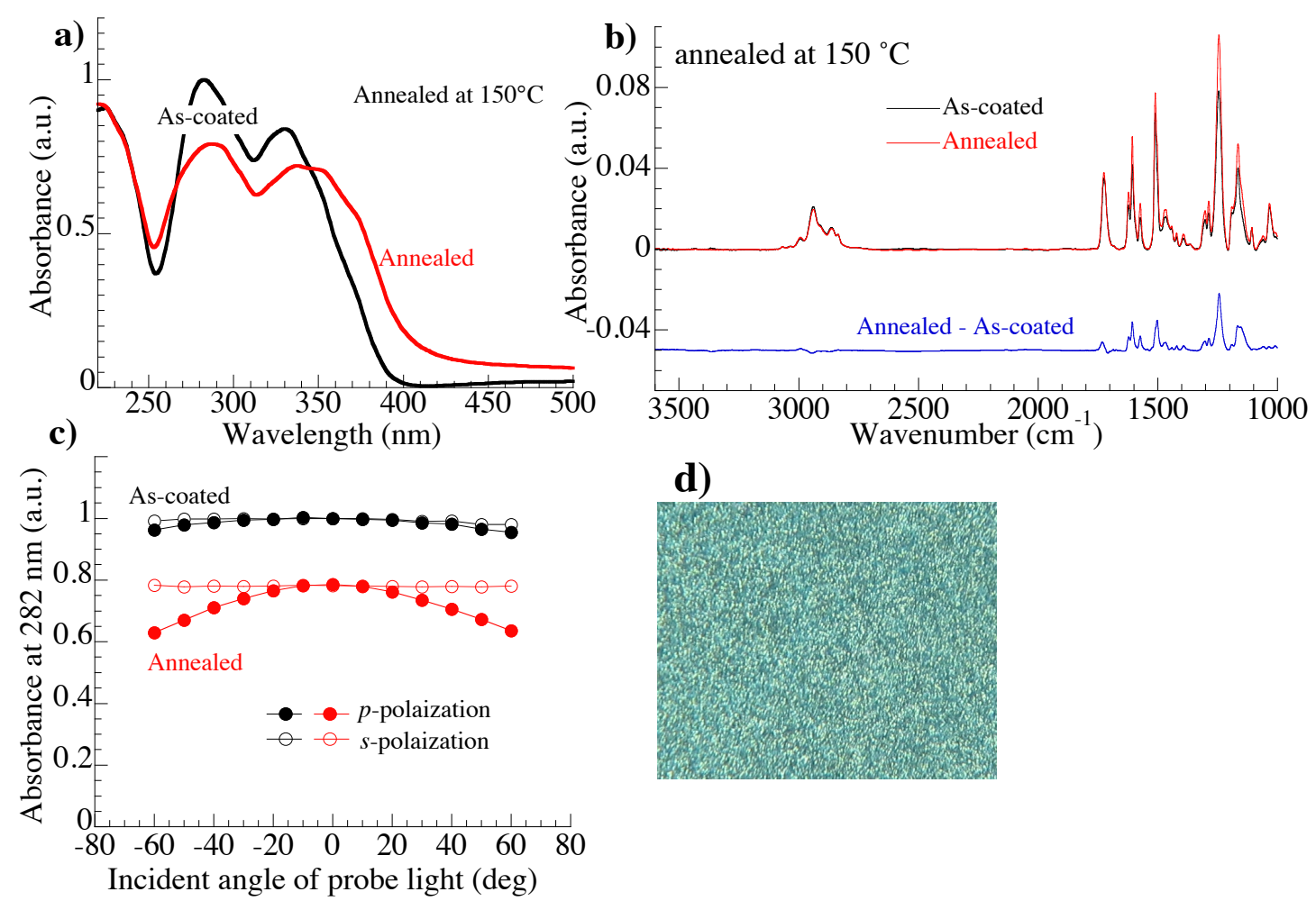

d)

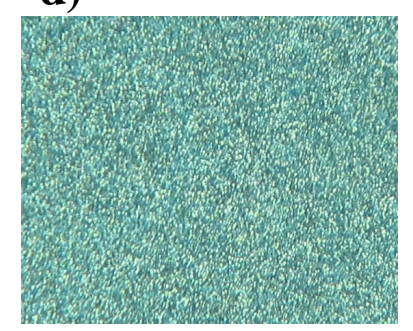

Figure S6. Change in (a) the UV-vis absorption and (b) the FT-IR spectra of the as-coated PNBAM film and after annealing at $150{ }^{\circ} \mathrm{C}$. (c) Angular dependence of the absorbance at $282 \mathrm{~nm}$ for the PNBAM film before and after annealing at $150{ }^{\circ} \mathrm{C}$ for 2 min. (d) POM photograph of the PNBAM film after annealing at $150^{\circ} \mathrm{C}$.
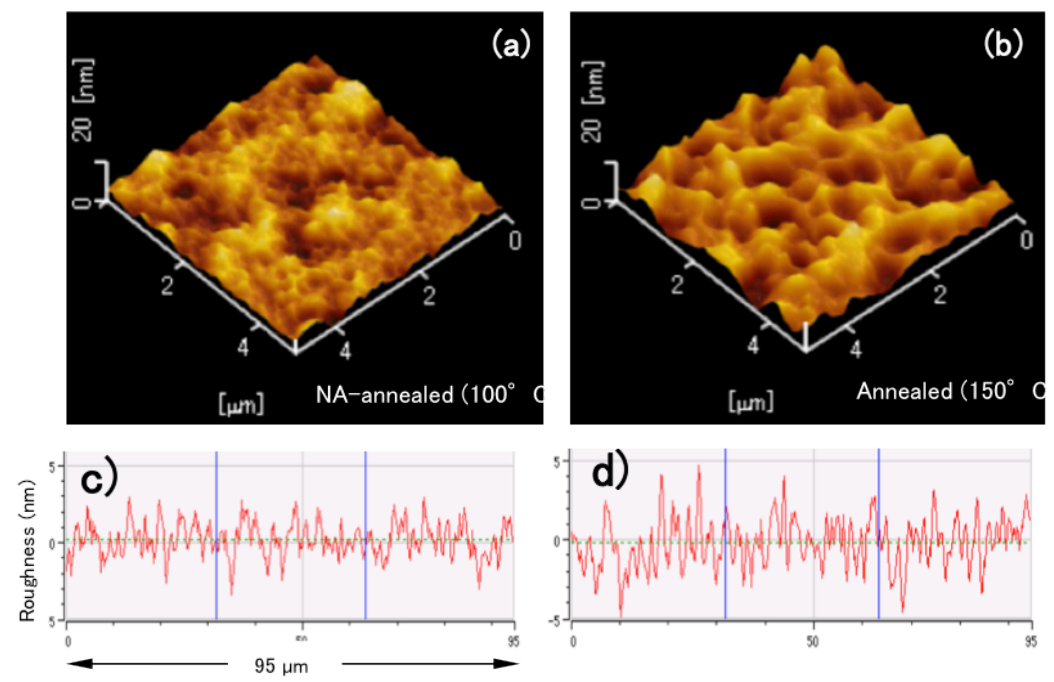

Figure S7. (a,b) Three-dimensitional images of the surface topologies $\left(5 \times 5 \mu \mathrm{m}^{2}\right.$, AFM tapping mode) and (c,d) the surface roughness ( $95 \mu \mathrm{m}$, VertScan) of PNBAM films. $(\mathrm{a}, \mathrm{c})$ NA-coated film after annealing at $100{ }^{\circ} \mathrm{C}$ and $(\mathrm{b}, \mathrm{d})$ the as-coated film after annealing at $150^{\circ} \mathrm{C}$. 

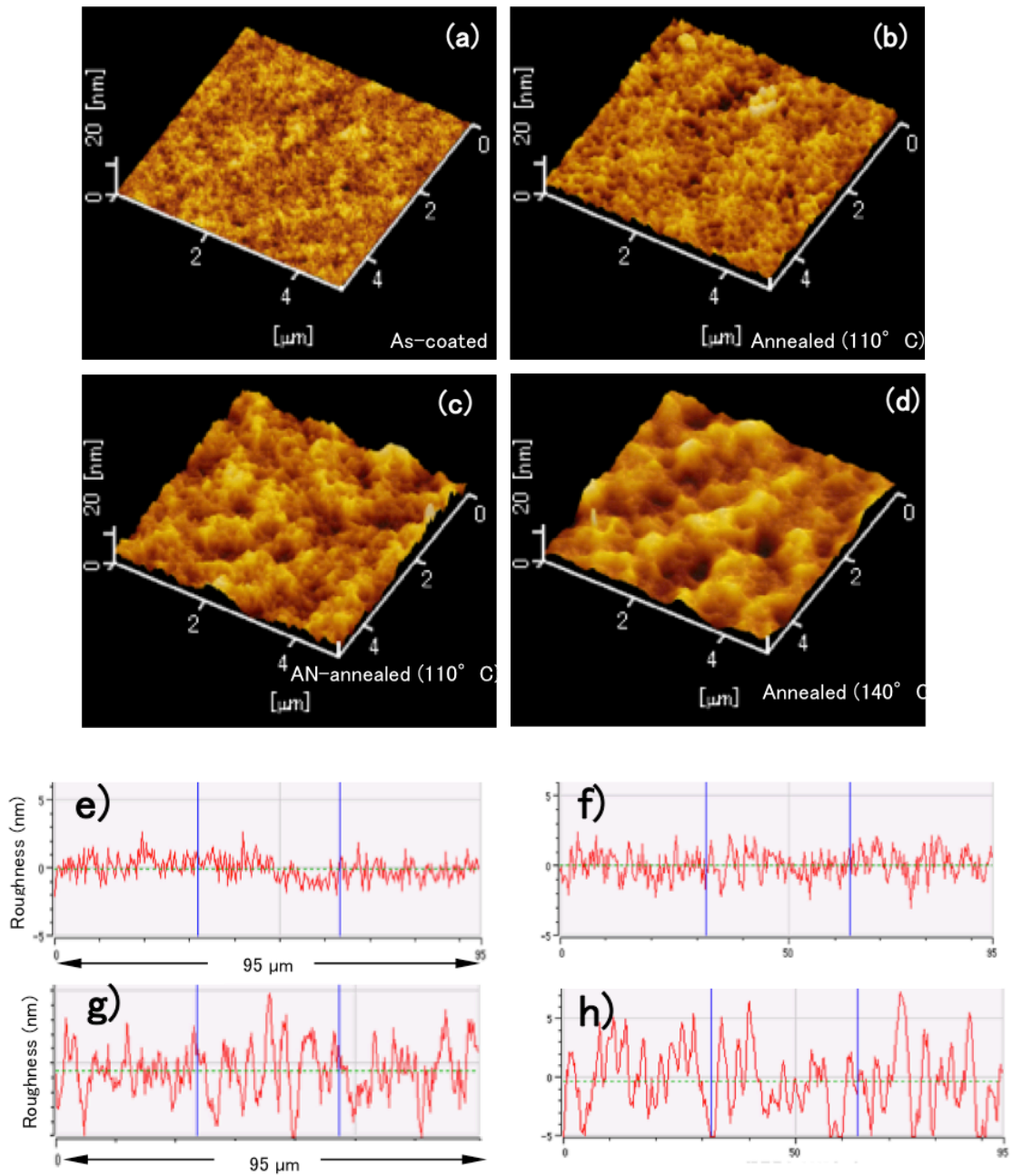

Figure S8. (a-d) Three-dimensional images of surface topologies $\left(5 \times 5 \mu \mathrm{m}^{2}\right.$, AFM tapping mode) and (e-h) the surface roughness (95 $\mu \mathrm{m}$, VertScan) of PMBM films. (a,e) As-coated film, $(\mathrm{b}, \mathrm{f})$ the as-coated film after annealing at $110{ }^{\circ} \mathrm{C},(\mathrm{c}, \mathrm{g})$ the AN-coated film after annealing at $110{ }^{\circ} \mathrm{C}$, and $(\mathrm{d}, \mathrm{h})$ the as-coated film after annealing at $140{ }^{\circ} \mathrm{C}$, 


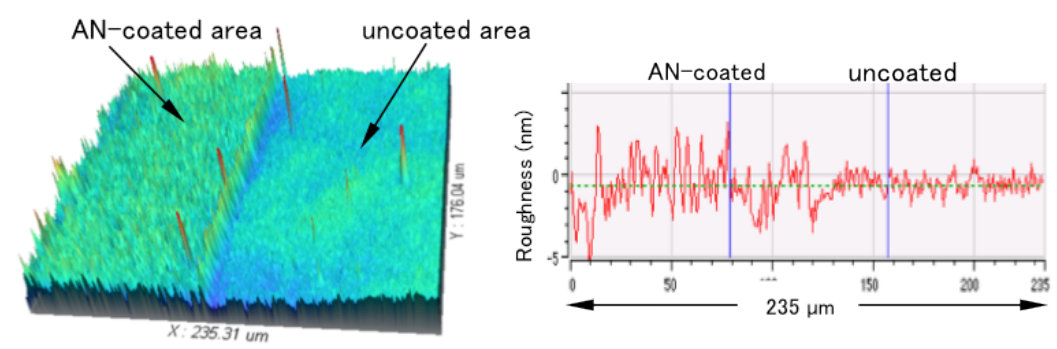

Figure S9. Three-dimensional image of the surface topology $\left(235 \times 176 \mu \mathrm{m}^{2}\right.$, surface profiler) and the surface roughness (235 $\mu \mathrm{m}$, surface profiler) of the boundary of the partly AN-coated PMBM film after annealing at $110{ }^{\circ} \mathrm{C}$. Arrows indicate the AN-coated and the uncoated areas.

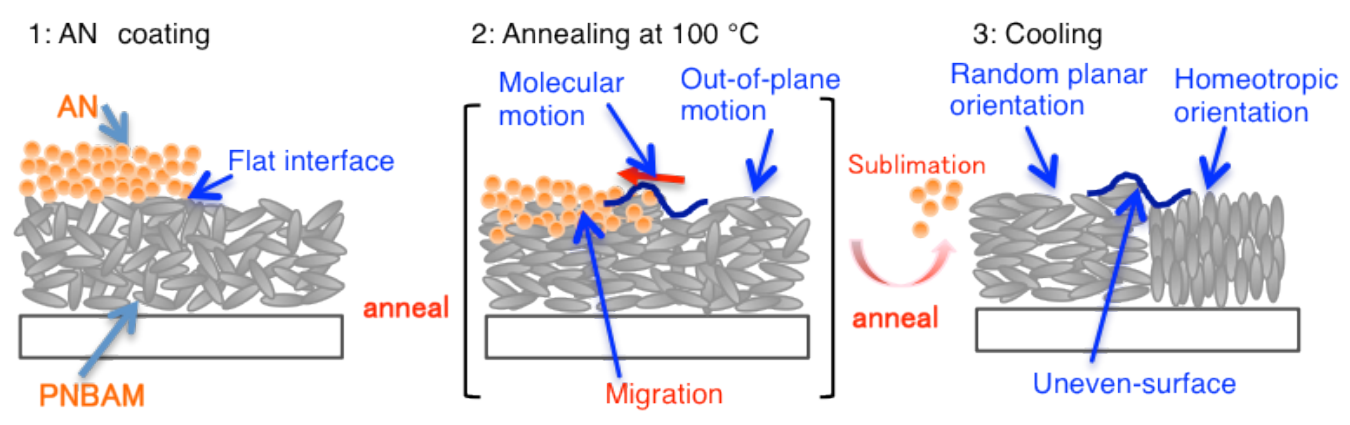

Figure S10. Schematic of unevenness formation at the boundary between the AN-coated and the uncoated areas of LCP films. 


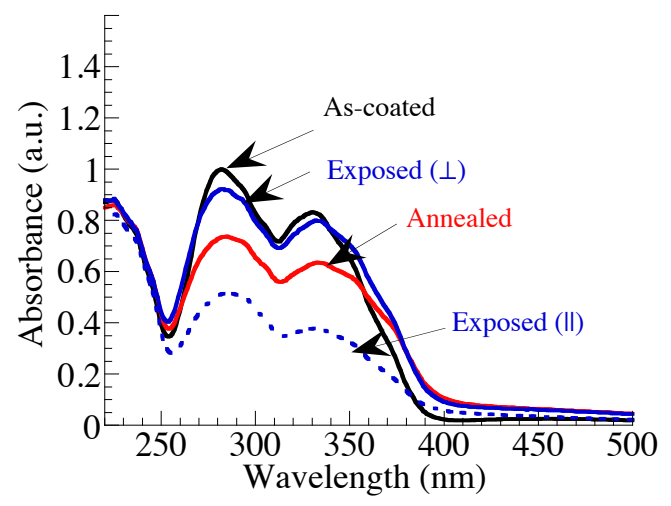

Figure S11. Changes in the polarized UV-vis absorption spectra of the NA-coated PNBAM film annealed at $100{ }^{\circ} \mathrm{C}$, and after subsequent irradiation with LP 365-nm light for $10 \mathrm{~J} / \mathrm{cm}^{2}$.

a)

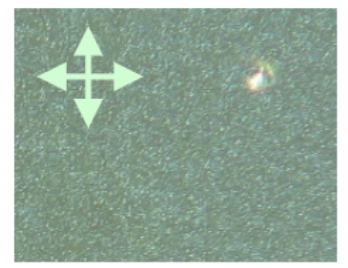

c)

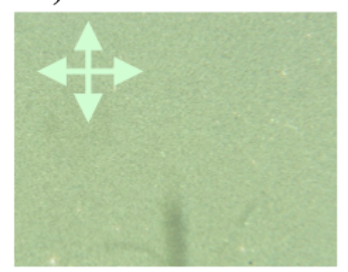

b)

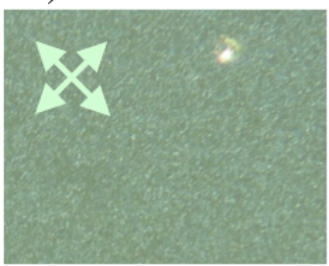

d)

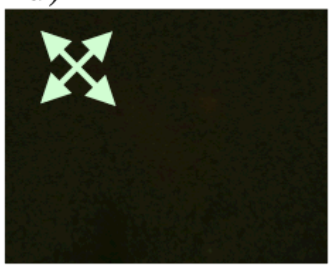

Figure S12. POM photographs of $(a, b)$ the $A N$-coated film after annealing at $100{ }^{\circ} \mathrm{C}$, and $(\mathrm{c}, \mathrm{d})$ subsequent exposure to LP $365-\mathrm{nm}$ light for $10 \mathrm{~J} / \mathrm{cm}^{2}$. Arrows indicate the polarizer and analyzer directions. 
a)

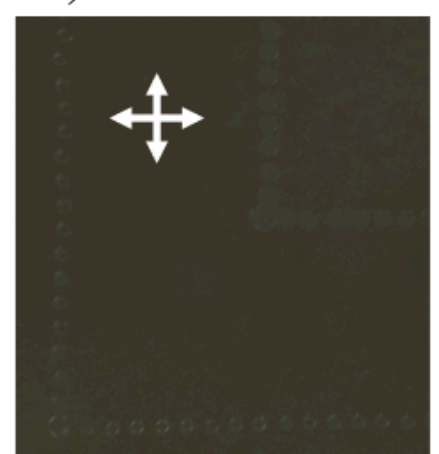

c)

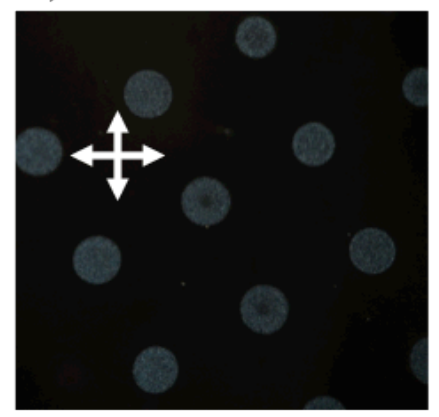

b)

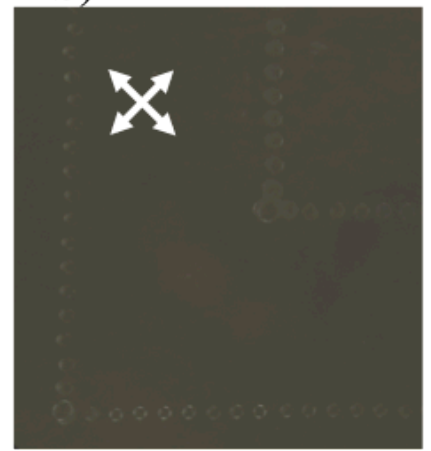

d)

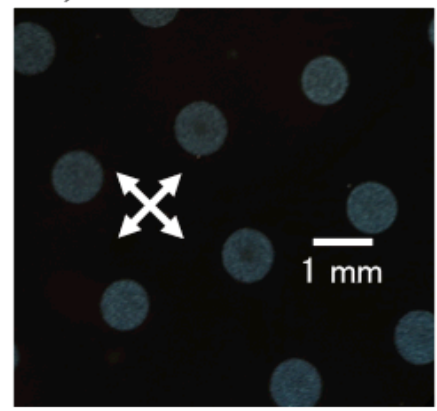

Figure S13. POM photographs of after annealing the AN-patterned coated PNBAM films at $100{ }^{\circ} \mathrm{C}$. (a,b) Inkjet-coated film. (c,d) Sublimation-coated film. White arrows indicate the polarizer and analyzer directions.

a)

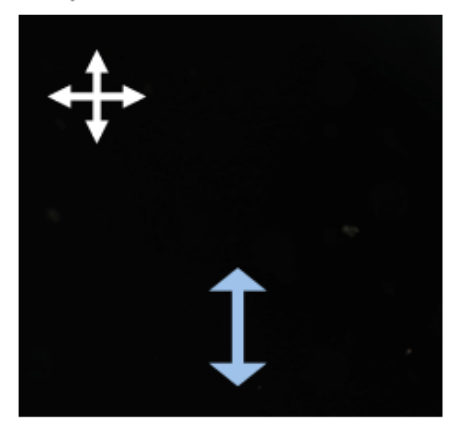

b)

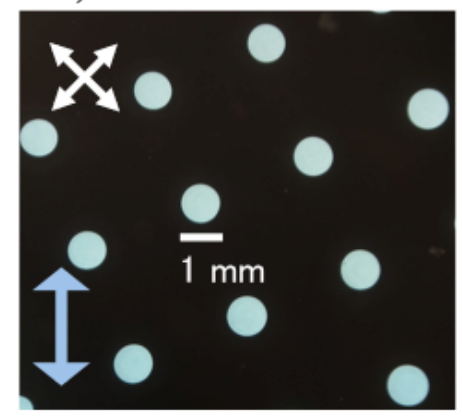

Figure S14. POM photographs of a patterned PNBAM film. The AN molecules are coated by sublimation, and the film is subsequently annealed at $100{ }^{\circ} \mathrm{C}$ and exposed to LP 365-nm light for $10 \mathrm{~J} / \mathrm{cm}^{2}$. White arrows indicate the polarizer and analyzer directions, and blue arrow is the in-plane orientation direction. 